\title{
A REVIEW ON EFFICIENCY FACTORS AND EQUATIONS OF VARIOUS SOLAR WATER HEATERS AND THEIR RELATIVE FIELD COMPONENTS
}

\author{
N. Sethupathi ${ }^{1}$, K.Vikramprasad ${ }^{1}$ and P. Maadeswaran ${ }^{2}$ \\ ${ }^{1}$ Department of Physics, Arignar Anna Govt. Arts College, \\ Namakkal- 637 002,Tamilnadu, India. \\ ${ }^{2}$ Department of Energy Studies, Periyar University, Salem-636 011 \\ *E-mail:sethupathi2011@gmail.com.
}

\section{ABSTRACT}

Solar water heater (SWH) is a cheap and eco- friendly human development system in the modern era. SWH is used in both homes and industries. This review paper is an overview of different types of SWH efficiency calculations, determination of thermal values like enthalpy, entropy, heat loss coefficient etc. It is a comprehensive and consolidated review of the solar energy equations needed for researchers in various nations. This paper provides the development of SWH's efficiency equations and also covers SWH's various components efficiency and the technology to understand the values of SWH equations and its various construction schemes.

Keywords: Solar energy, solar water heater, and its components calculating formulas and equation.

(c) RASĀYAN. All rights reserved

\section{INTRODUCTION}

For doing any work, power or might is a serious factor. A familiar might is a solar energy. Solar energy is a standard source. Solar energy is the most common alternative because of its unique or specialized property of eco-good nature. ${ }^{1-5}$ Solar energy plays a major role in energy demand in the day to day life. Solar energy is non-complex renewable energy. Solar energy is a technology that develops called a sector solar water heater. Hot water is needed for the society, particularly, in industrials, hotels, hospitals, homes etc. ${ }^{6}$ For the social growth and wellness, the Sun water heater is one of the backbones. Warm water getting via solar energy is the world famous application. Solar water heater is employed in the home hold energy utilization. ${ }^{7,8}$ Around the world, the most home energy used to in either heat or cool. For this reason, the solar water heater is a friendly one, so for free source, sun water heaters and Free energy ovens, free energy stills, Nature lightens having various designs and models, parts etc. They have different types of theoretical equations for efficiency and other factor's calculations. That is why we are interested in consolidating and reviewing the calculating formulas and equations of solar water heaters and other relative components. ${ }^{9-13}$

\section{Various Solar Water Heating Systems Efficiency Equations}

1. Solar thermal collector (Flat type sun power water heater)

The solar thermal collector is generally made up of the rectangular aluminum pipe. The new nature power water heating system is investigated on below the following and calculations. It is agreed to home diminutive situational constrictions in situational systems.

The design of New Flat Plate Collector with the following, Aluminum box with one large surface open having size $(900 \mathrm{~mm}$ X $600 \mathrm{mmX} 120 \mathrm{~mm})$ and a Glass $5 \mathrm{~mm}$ thick to cover the box large open surface. Black paint for absorbing solar radiation. The insulation layer $\left(860 \mathrm{~mm}\right.$ X 500mm X 30mm) ${ }^{14}$

Collector panel efficiency is the ratio between the rates of heat $(\mathrm{Q})$ is transferred to a fluid divided by the amount of solar radiation on the cover plate area.

$$
\eta=\frac{Q}{A G}
$$

Rasayan J. Chem., 10(3), 778-783(2017)

http://dx.doi.org/10.7324/RJC.2017.1031737 


$$
\eta=\frac{\mathrm{mC}_{\mathrm{p}}\left(\mathrm{T}_{\text {out }}-\mathrm{T}_{\text {in }}\right)}{\mathrm{AG}}
$$

Where, $\mathrm{Q}=$ the energy absorbed by the collector, $\left(\mathrm{W} / \mathrm{m}^{2}\right)$

$\mathrm{A}=$ Area of the collector, $\left(\mathrm{m}^{2}\right), \mathrm{G}=$ Total solar radiation intensity $\left(\mathrm{W} / \mathrm{m}^{2}\right)$

$\mathrm{T}_{\text {in }} \& \mathrm{~T}_{\text {out }}=$ The temperature of the incoming \& outgoing water $\left({ }^{\circ} \mathrm{C}\right) .{ }^{15}$

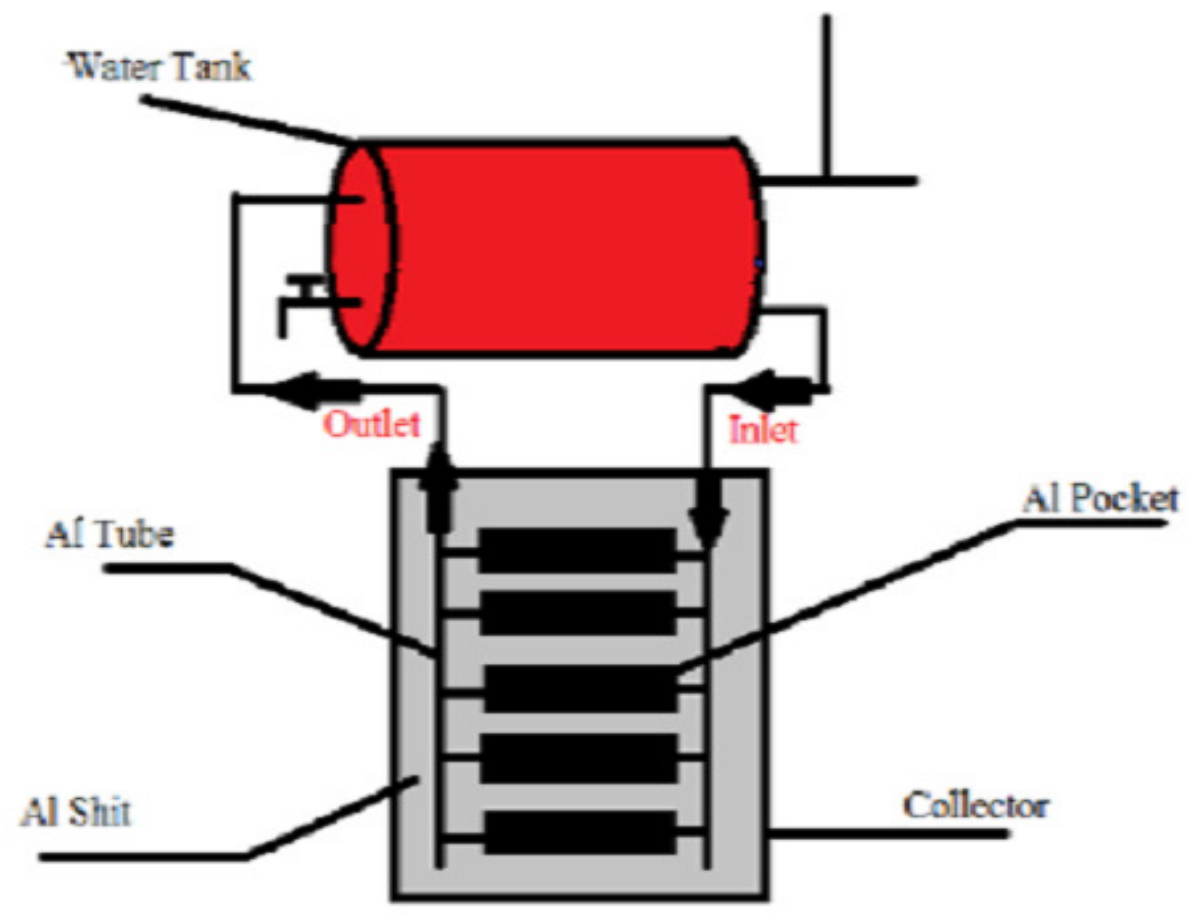

Fig.-1: Assembly of Solar Water Heater

\section{Water saving unit with crowd type SWH with closely connected}

This is useful to closely connected collector water saving unit is mere type SWH. The compounds parabolic collector symmetric species can issue in crowd type solar systems with competent water heating by utilizing the irregular allotment of sunbeams brightness, on the cylindrical imbibe superficies.

Warm ability is derived by below equation:

$$
\text { Ability equation } \mathrm{E}_{\mathrm{i}}=\int_{0}^{24 h r s} I \mathrm{X} \text { Adt }
$$

Where, $\mathrm{I}=$ Sun brightness on $\mathrm{SWH} \mathrm{MJ} / \mathrm{M}_{2}$

$\mathrm{T}_{1}=$ Inner heat in copper line ${ }^{\circ} \mathrm{C}$

$\mathrm{T}_{2}=$ Inner heat in model ${ }^{\circ} \mathrm{C}$

$\mathrm{T}_{3}=$ Storage tank heat ${ }^{\circ} \mathrm{C}$

$\mathrm{T}_{4}=$ Inner heat of SWH ${ }^{\circ} \mathrm{C}$

$\mathrm{T}_{5}=$ Ambient heat nigh setup ${ }^{\mathrm{O}} \mathrm{C}$

Energy Output (in terms of energy): $\mathrm{E}_{\mathrm{o}}=\dot{\mathrm{m}} c_{p}(\Delta T)$

Overall Efficiency (Full Day) $\eta=\mathrm{E}_{0} / \mathrm{E}_{\mathrm{i}} \mathrm{X} 100 \%{ }^{16-18}$

\section{A parabolic dish solar water heater}

This is useful for parabolic dish type solar water heaters. Thecondensationratiois viewed as the ratio of the opening region to the Imbibe region. 
RASĀYAN J. Chem.

Vol. 10 | No. 3 |778 - 783 | July - September | 2017

$$
\mathrm{C}=\mathrm{X}_{\mathrm{a}} / \mathrm{X}_{\mathrm{abs}}
$$

Where, $X_{a}=$ Aperture area; $X_{a b s}=$ Absorber area

Optical efficiency $\eta_{0}$ is describe as the ratio of the power imbibe by the imbibe to the energy happening on the condensation aperture. It contains the consequence of class lens area, frame and reflection transmittal losses, Tracing exactness, Shading, Receptacle-cover transmittal, the absorptance of the absorber and Sunbeam incidence effects.

Warm ability is derived by:

$$
\eta_{0}=X_{\text {abs }} / A_{a} I_{D}
$$

Where, $\mathrm{X}_{\mathrm{abs}}=$ Amount of power absorbed by the absorber

$\mathrm{A}_{\mathrm{a}}=$ Aperture area

$\mathrm{I}_{\mathrm{D}}=$ Longterm average direction of radiation

The warm ability circumscribes the rate of purpose energy liberates to the energy belonging at the condenser aperture:

$$
\eta_{\text {the }}=\rho \mathrm{Vc}_{\mathrm{pf}}\left(\mathrm{H}_{2}-\mathrm{H}_{1}\right) / \mathrm{X}
$$

Where, $\mathrm{X}=$ Sun brightness

$\mathrm{H}_{1}=$ Temperature of hot warm fluid penetrate the collector

$\mathrm{H}_{2}=$ Temperature of hot warm fluid withdrawing the collector

The instantaneous thermal efficiency:

$$
\eta=F_{R}\left(\eta_{0}-\frac{U_{L}\left(T_{L}-T_{a}\right)}{I_{b} C}\right)
$$

The immediate warm ability is hanging on two sides of measure, Note that concentrator scheme limits and the range characterizing the working levels. The optical ability, heat loss coefficient and warm displace agent is the intent hanging limits as long as the solar flux, entrance the fluid temperature and the ambient temperature set bounds to the working circumstances. ${ }^{19-22}$

\section{Saving tank SWH level and integrated collector}

It is an integrated storage collector is made up tank triple the double area of sun absorber and saving tank.

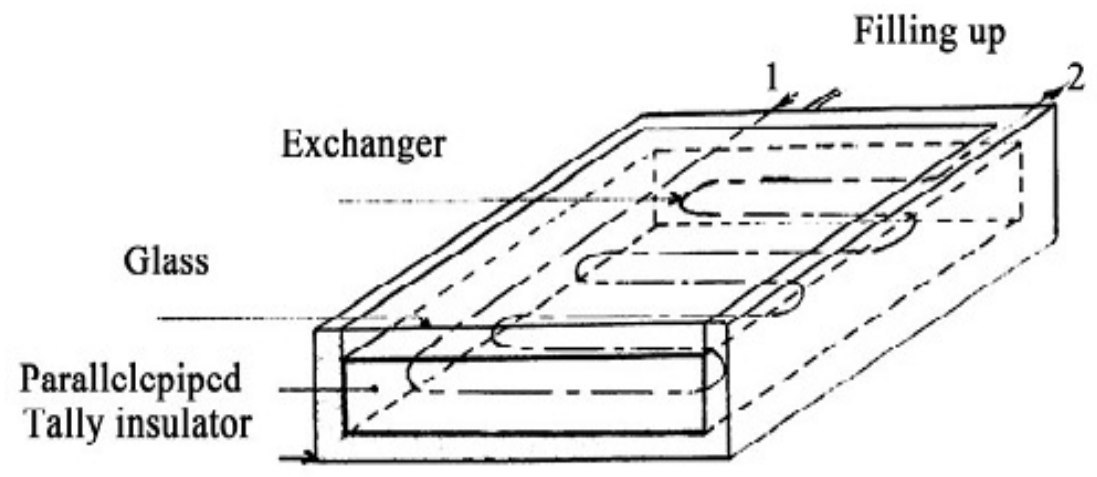

Fig.-2: Integrated collector storage with exchanger

The disperse emission of rays (i.e emitted or throw back by the air the sky environment got by the level drought in the covering of pure sky circumstances.

$$
\mathrm{G}_{(\mathrm{i})}=\mathrm{I}_{\mathrm{D}} \cdot \mathrm{COSu}+\mathrm{D}_{(\mathrm{i})}
$$


Final Energy,

$$
\mathrm{W}_{0}=\frac{2}{\pi} \cdot \mathrm{G}(\mathrm{i}) \cdot \Delta T_{0}
$$

The collector ability is denoted by the in-out way, these parts define in letting the collector temperature for the time of complete day (Earth hours) We found the water, heat level on their base levels(less value, the average value, and high value) and the incidental sun flowing.

$$
\eta=\frac{\operatorname{m} \cdot \operatorname{cp} \cdot \Delta T}{S \cdot \Sigma I N \cdot \Delta T}
$$

Where, $\mathrm{M}=$ Heap of water

$\mathrm{CP}=$ Peculiar heat of water

$\mathrm{T}=$ Heat increase

The output enabled us to plot the following curves. ${ }^{23}$

$$
\begin{aligned}
& \mathrm{S}=\text { absorber surface } \\
& \mathrm{T}=\text { time of reading taken } \\
& \mathrm{IN}=\text { happening sun flux or flow }
\end{aligned}
$$

\section{Shell-Encapsulated Solar Collector with the Compound Surface Concentrators}

It can be suitable for the shell-encapsulated solar collector. The design of sun collector is based on the combination of novel compound bend or crook area aluminium concentric solar recipient. It will be contained in glass evacuated tube. ${ }^{24}$

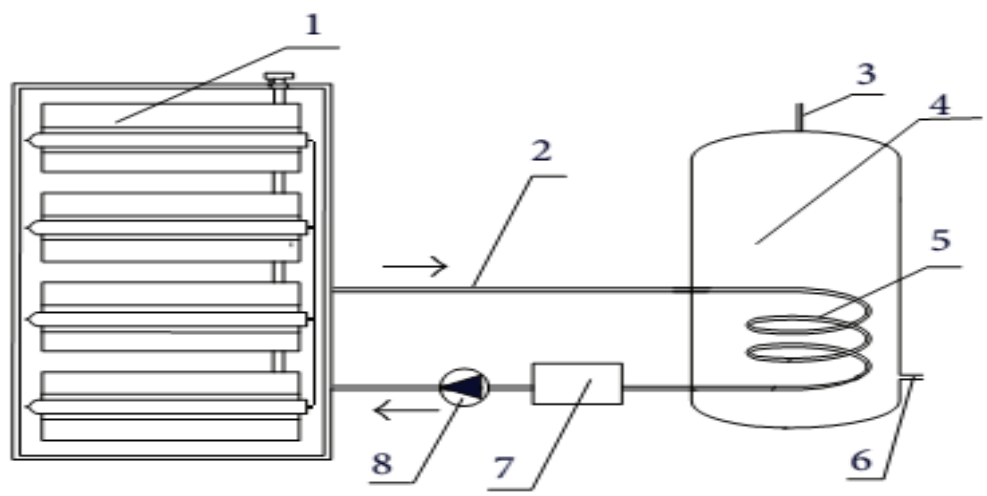

Where,

Fig.-3: Schematic practical setup for trail prototype shell-encapsulated sun collector.

(1) A new combine bend area concentrator

(2) Circulating pipe

(3) Water outlet

(4) Water tank
(5) Heat exchange coil

(6) Water inlet

(7) Oil tank

(8) Pump

The average efficiency is a key parameter to characterize a solar collector, and it may be defined as follows,

$$
\eta_{d}=M C_{p}\left(t_{e}-t_{s}\right) / A_{c} H
$$

Where, $\eta_{d}$ is the daily average efficiency, $M$ and $C_{p}$ are the amount and specific heat of water, $t_{s}$ is the startingaverage heat of the water tank $\left({ }^{\circ} \mathrm{C}\right), t_{e}$ is the conclusive temperature of the water tank. $\left({ }^{\circ} \mathrm{C}\right), H$ is the daily cumulative solar radiation exposure $\left(\mathrm{MJ} / \mathrm{m}^{2}\right)$, and $A_{c}$ is the aperture area of the sun collector. ${ }^{25}$

\section{Sun Temperature setup for home top-Evaluationingathering sky rain water}

The calculations are well matched at the box-type solar water heater, maybe an appropriate household water technology. 


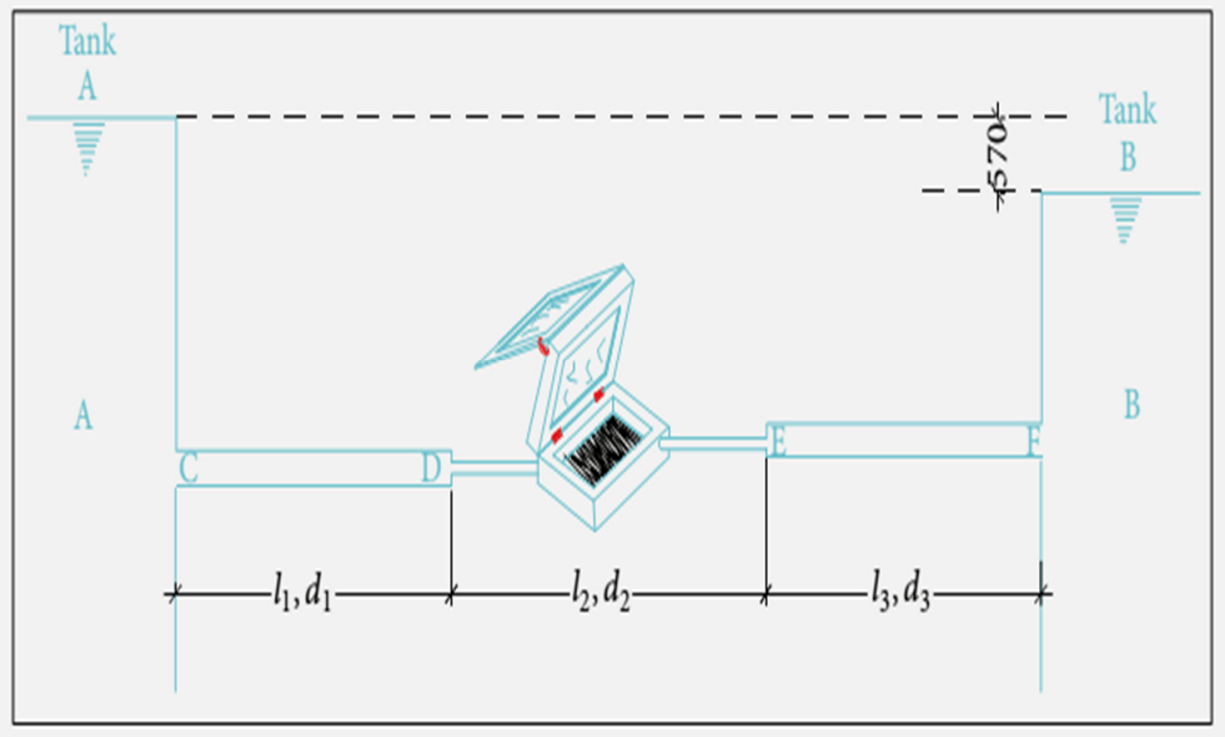

Fig.-4: Block diagram of SWH setup.

Heat ability of an SWH or free energy nature cooking system is concluded from water heating trail appliance the narration,

$$
\eta=(M w C w+M c u C c u) \sum \Delta T / I A \Delta t
$$

Where, $\eta=$ heat ability $(\%), M w=$ weight of water $(\mathrm{Kg}), M c u=$ weight of the copper pipe $(\mathrm{Kg}), C w=$ Peculiar heat level of water $\left(4200 \mathrm{~J} \mathrm{Kg}^{-1} \circ \mathrm{K}^{-1}\right), C c u=$ Peculiar heatlevel capacity of copper pipe (400 J $\left.\mathrm{Kg}^{-10} \mathrm{~K}^{-1}\right), I=$ total solar emissionof rays $\left(\mathrm{W} \mathrm{m}^{-2}\right), A=$ area of absorber plate $(\mathrm{m} 2), \Delta T=$ difference in temperature $(\mathrm{C})$, and $\Delta t=$ difference in time (seconds). ${ }^{26}$

\section{Empty pipe based sun rays collector purpose D-12 ending temperature fluid combine design with Parabolic}

This is suitable for empty pipe based sun rays collector purpose D-12 ending temperature fluid combine designed with Parabolic through.This equation for empty pipe based sun rays collector purpose D-12 ending temperature fluid combine designed with parabolic importunate hot water production. The efficiency calculations for empty tube collector were investigated by Ruobing Liang et al. The formula for calculating parabolic trough collector efficiency is listed by $\mathrm{Li}$ et al.

The ratio of temperature gained by the water to heat lost by the terminal will give the heating efficiency. ${ }^{27-29}$

Where,

$$
\text { Heat gained by the water, } Q_{W}=\mathrm{m}_{\mathrm{w}}\left(T_{w i}-T_{w i}\right)
$$

$\mathrm{m}_{\mathrm{w}}=$ Mass flow rate of thermal in $\mathrm{kg} / \mathrm{s}$

$T_{w i}=$ Inlet temperature of water in ${ }^{\circ} \mathrm{C}$

$Q_{W}=$ Heat gained by the water in w

Heat lost by therminol, $Q_{t}=\mathrm{m}_{\mathrm{t}}\left(T_{t i}-T_{t o}\right)$

Where,

$Q_{t}=$ Heat lost by therminol in $\mathrm{w}$

$\mathrm{m}_{\mathrm{t}}=$ Weight flow rate of water in $\mathrm{kg} / \mathrm{s}$

$T_{t i}=$ Inlet temperature of therminol, in ${ }^{\circ} \mathrm{C}$

$T_{t o}=$ Outlet temperature of therminol, in ${ }^{\circ} \mathrm{C}$ 
Heating efficiency, $\eta=Q_{w} / Q_{t}$

Heating efficiency in \%

Where,

$Q_{w}=$ Heat gained by the water in w

$Q_{t}=$ Heat lost by therminol in $\mathrm{w}$.

\section{CONCLUSION}

Nowadays, solar water heating systems are constructed with various setups and arrangements. Solar water heating technique is very successful in the research area of renewable energy utilizations. A broad review of this features and related components are considered to efficiency and other factors to (increase) performance in solar water heaters for future. This type of research is due to the environmental concerns and economic benefits.

\section{REFERENCES}

1. S. Chandhari, N. Parmar and H. N. Panchal, Int. J. Res. Engg. Tech., 4, 50 (2013).

2. Kishan Patel, Pragna Patel and Jain Patel, Int. J. Res. Engg. Tech., 3, 146 (2012).

3. R. Shukla, K. Sumathy, P. Erickson and J.Gong, Renewable and Sustainable Energy Review, 19, 173 (2013).

4. Solar Energy Fundamental and Application First Revised Edition, Tata McGraw-Hill (2000).

5. Alokkumar, J. Mech. Civil Engineering,7, 63(2013).

6. Solar Energy Principle of Thermal Collection and Storage, The McGraw-Hill Companies (2010).

7. Mahesh V. Kulkarni, and D. S. Deshmukh, International Journal of Engineering Research and Technology, 287, (2016).

8. D. S. Deshmukh, M. V. Raolani, and M.V. Kulkarni, Int. Con. Adv. Ener. Tech. on March 29, (2013).

9. K. Kalidasa Murugavel, and K. Srithar, Ren. Ener. 36, 612 (2011).

10. A. Ahsan, Kh. M. ShafiulIslam, T. Fukuhara and A. H. Ghazali, Desalination, 260, 172 (2010).

11. I.L. Mohammed J. Engg. Res. App, 2, 822 (2012).

12. Solar Energy, Tata McGraw-Hill, (2000).

13. S. A. Klein, Solar Energy, 19, 325 (1977).

14. I. L. Mohammed Development and Performance Analysis of a Solar Tracking Parabolic Collector. Ph.D. Thesis, Bayero University Kano, Nigeria 184,(2009).

15. R. B. Slama, Ener. Pow. Engg. 4, 67 (2012).

16. R. B. Slama, Tunisian Ener. J.44, 37(1997).

17. The Solar Radiation, Thermal Conversion and Applications, Technique and Documentation,(1980).

18. H. Zinian, J. ActaEnergiae Solaris Sinica, 13, 1 (1992).

19. J. H. Li, and Q. Jiang, J. Act. Ener. Sol. Sin. 22, 131(2001).

20. S.-Y. Yan, R. Tian, S. Hou, and L.N. Zhang, J. Engg. Thermophysical, 29, 323(2008).

21. S. Mahavar, N. Sengar, P. Rajawat, M. Verma, and P. Dashora, Ren. Ener. 47, 67 (2012).

22. V. Meera, and M. M. Ahammed, Wat. Sci. Tech. Wat. Supp. 8,153 (2008).

23. W. Heaselgrave, N. Patel, S. Kilvington, S. C. Kehoe, and K. G. McGuigan, Lett. App. Mic.43, 125 (2006).

24. K. G. McGuigan, F. Mendez-Hermida, and J. A. Castro-Hermida, J. App. Micro. 101, 453 (2006).

25. P. Selvakumar, P. Somasundram, and P. Thangavel, Ener. Conversion Management. 6, (2014)

26. R. Liang, L. Ma, J. Zhang, and D. Zhao, Heat Mass Transfer, 48, 989 (2012).

27. C. Li, R. Z. Wang, L. W. Wang, T. X. Li, and Y. Chen, Ren. Ener. 57, 223(2013).

28. S. J. Kline, and F. A. McClintock, Mec. Engg. 75, 3 (1953).

29. S. J. Kline, ASME J. Flu. Engg. 117, 153 (1985).

[RJC-1737/2017] 